Article

\title{
Examining the Use of Systemic Approach for Adoption of Systems Thinking in Organizations
}

\author{
Prasad Vemuri ${ }^{1, *,+}$ and Gene Bellinger ${ }^{2}$ \\ 1 Vemuri Consultants Private Limited, Padmavathinagar, Khairtabad Hyderabad 500004, India \\ 2 Systems Thinking World Inc., Kill Devil Hills, NC 27948, USA; systemswiki@gmail.com \\ * Correspondence: vcsprasad@gmail.com; Tel.: +91-40-2339-0223 or +91-99-4967-0810 \\ + This author has been deceased.
}

Received: 8 April 2017; Accepted: 22 June 2017; Published: 28 June 2017

\begin{abstract}
The need for systems thinking (ST) in organizations is being increasingly felt, and sustained effort towards nurturing ST in organizations is still rare. Some companies that tried it earlier were not so successful. One of the reasons for this problem is that the implementation is done more with a reductionist mindset rather than a systemic mindset. It is no doubt challenging for managers so accustomed to reductionist thinking to cultivate the habits of systems thinking. This paper examines the use of a systemic approach for the successful adoption of systems thinking in organizations. The systemic approach needs a good system model for the systematic guidance of the implementation. The systemic model used in this study is a spirit, mind, and body model (SMB)—a holistic model taken from the spiritual lore which emphasizes the need for the alignment of spirit, mind, and body in order to achieve human excellence. We extended this model for use in an organizational context, and defined the systems of the spirit, systems of the mind, and systems of the body for an organization. Systems of the spirit are related to the leadership system, systems of the mind to the learning and change management systems, and systems of the body to the supporting systems such as tools and technology. We used such a model earlier to explain the suboptimal results in the implementation of capability maturity models (CMM) in software companies in India. In this paper, we used this model to explain the rather unsatisfactory results in the implementation of ST in companies like Ford and the satisfactory results in the implementation of "work out" at GE. "Work out" is a five-step process in which ST is a prominent step. We argued whether "work out" can be a good warm-up step that can prepare the organization for successful ST implementation. The study shows that the SMB framework is helpful in conducting an intelligent discourse about the implementation of ST-like initiatives in companies and has excellent potential for use as a guide for ST implementation in organizations.
\end{abstract}

Keywords: leadership; systems thinking; reductionist thinking; adoption; systems of spirit; systems of mind; systems of body; learning levels; change management

\section{Introduction}

Systems thinking (ST) was in fashion in the 1960s and 1970s, only to fade away for a variety of reasons. It never made the leap into the mainstream activities of business organizations. Companies shifted to approaches such as strategic planning and management to understand issues related to positioning and performance. As of late, however, systems thinking seems to be making a comeback because of several limitations being felt in the currently-used reductionist thinking-particularly in solving complex problems (e.g., [1]). It is important to note that implementing ST in organizations is difficult, although there are models (e.g., spirit, mind, and body (SMB); Viable Systems; Living Systems, etc.) and tools (e.g., iThink, Vensim, Insight Maker, Kumu, etc.) which are essential and support the effort well. 
An organization is a large family of people with a complex web of interactions taking place between them. Systems thinking is about understanding these interactions and interconnections and identifying the leverage points to solve the problems in the organization. This approach contrasts with the traditional reductionist thinking (RT) which studies systems by breaking them into separate smaller elements for ease of analysis using simple linear cause-effect relationships (example, [2]). Such an approach has the danger of working in silos without having the larger organizational context in view, and therefore has limited effectiveness in addressing the ever-increasing complexity of problems being faced by many organizations (example, [3,4]). The kind of work many managers do is very narrowly-based, involving highly-specialized tasks, and therefore often limits them to reductionist thinking. Since systems thinking is not their normal mode of thought, it is hard to form it as a natural habit [5]. The key differences in habits of reductionist thinkers when compared with systems thinkers are given in Table 1.

Because of these differences, the implementation of ST in organizations remains a major challenge, although its need is recognized. Some of the challenges for implementation can be summarized as under $[1,6]$ :

- The language used in understanding and the use of ST is significantly different than that being routinely used in mainstream activities of businesses, which are largely based on reductionist thinking [6].

- The significant new learning based largely on a different set of concepts and tools ends up acting as a deterrent.

- Many are not clear on how to complement one with the other if both ST and RT need to coexist.

- Convincing business cases with examples are still rare to support its ready adoption in business organizations.

- Even if well-meaning passionate people somehow try to manage the above shortcomings and initiate ST in small groups in the organization, successful organization-wide adoption is still a major challenge. The current paper examines this challenge more critically.

Table 1. Habits of the Systems Thinker vs. Reductionist Thinker †.

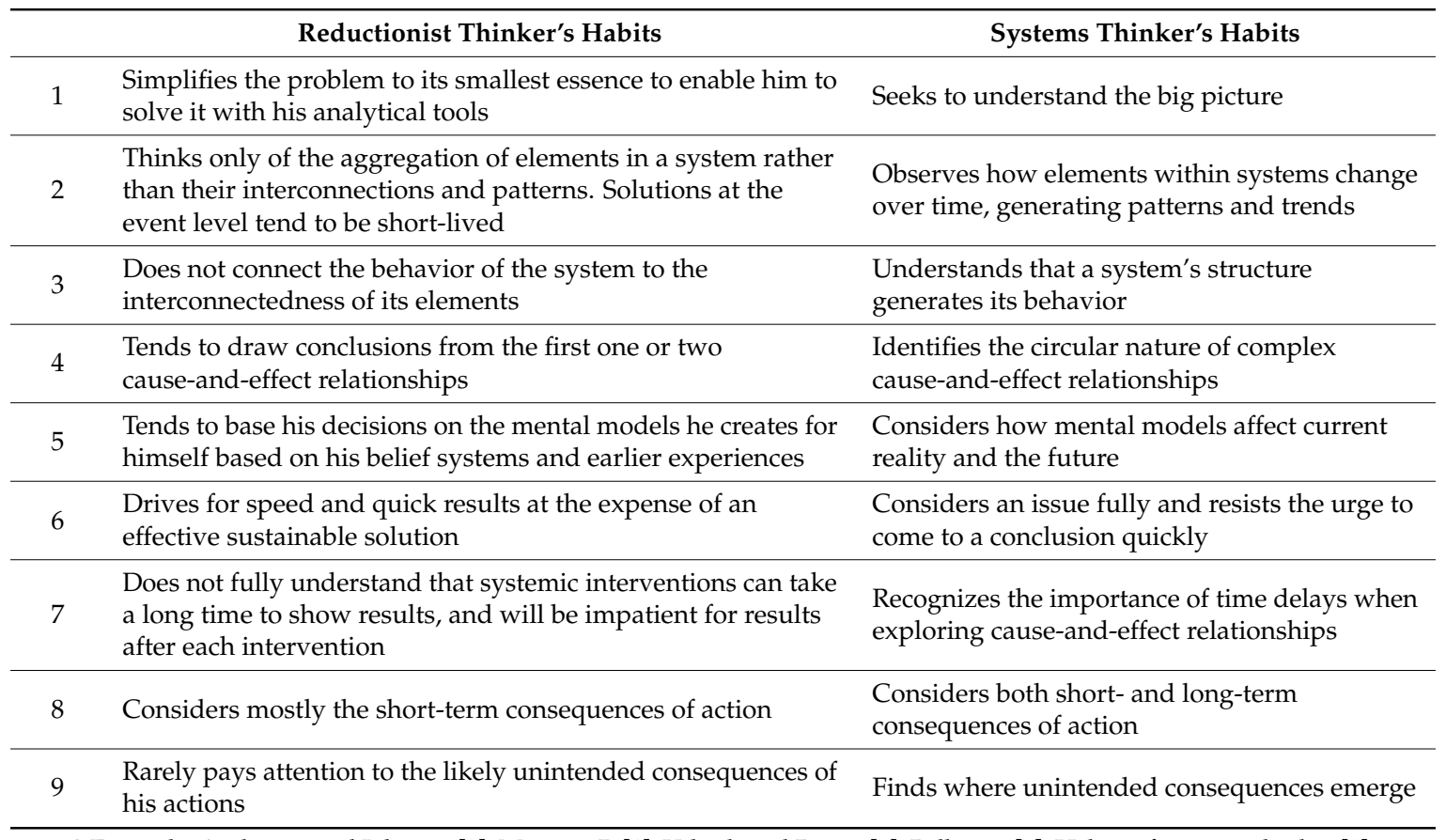

† Example, Anderson and Johnson [3], Morgan, P. [1], Velardi and Rouse [5], Bellinger [7], Habits of systems thinker [8]. 
The successful organization-wide adoption of any radically new initiative such as ST involves significant change in the way people think and act (example, Table 1). Such a change amounts to an organizational transformation. Purchase et al. [9] emphasized the need for a holistic approach for the success of such transformations. Earlier, through their study of some Indian software companies, Prasad et al. [10] observed the need for a systemic approach in order to derive the expected benefits from the implementation of radical process initiatives such as the capability maturity models (CMM). In the present paper, we examined the need for a systemic approach for the successful implementation of ST in organizations.

The study is done using two already known industry cases: one, a somewhat unsuccessful case-that of the implementation of ST in Ford Motor company [11]; and the other, a successful case-that of the implementation of the "work out" initiative at GE. "Work out" is a five-step process, with the development of systems thinking being one of its prominent steps [12]. The terms "unsuccessful" and "failure" are used in this paper to mean the inability of the organization to make an organization-wide implementation of the initiative, even if it succeeds to do so in small pockets. A generic model developed earlier by us [10] to study the adoption of organization-wide implementation of CMM-like initiatives is used for the current study. The basic ideas for the model were taken from Nori's work (e.g., [13]). Details of the model are given hereunder.

\section{The Spirit, Mind, Body Model (SMB)}

The basic concept of the model is taken from the spiritual lore which emphasizes the need for alignment of spirit, mind, and body for the achievement of human excellence (e.g., [14]).

Based on this understanding, the argument in this paper is that the spirit, mind, body alignment of the organization is required for effective change towards its overall improvement.

Towards this end, the spirit of the organization is defined in terms of "systems of the spirit", the mind of the organization in terms of "systems of the mind", and the body of the organization in terms of "systems of the body". The model is represented by a Venn diagram as shown in Figure 1.

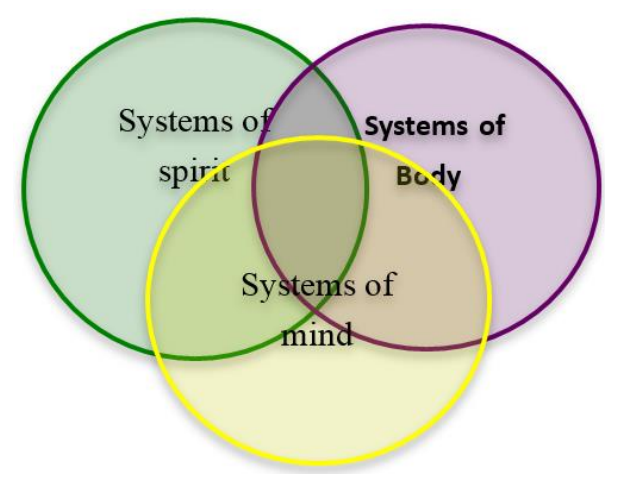

Figure 1. Spirit, Mind, Body (SMB) model for the adoption of Systems Thinking (ST) in organizations.

\section{Systems of the Spirit}

Systems of the spirit essentially refers to the leadership system meant to impart the right vision, inspiration, and energy, and provide the right systems and structures for the initiative to take root in the organization. The leadership's spirit should enable the many initial inconveniences faced by people in working on the new initiative to be overcome, and should impart the necessary endurance to make it happen. "The essence of leadership is not just giving resources or even providing visions. It is offering one's spirit to the organization which means creating an environment where people gravitate in the direction of the leadership, not through a mandate but through their own choice. Only with the right leadership, will the environment and enablers be in place, the resources be made available, and the roadblocks be dismantled for the new initiative to take root in the organization" [15]. 
Thus, the Systems of Spirit in Table 2 includes vision, mission, values, strategy, governance, communication, and feedback. "Values" are meant to impart the necessary behavioral discipline in the implementation of the new initiative. Examples are openness and endurance for new learning for adoption. "Strategy" is related to implementation decisions. For example, should there be different training levels-one basic level for the whole organization, and the other, an advanced level for specific areas of businesses, what should be the level of exposure to supporting groups, what kind of projects should be taken for ST-based implementation, etc. "Governance" includes a clear definition of roles and responsibilities of different people at different levels in the organization who are involved in leadership positions [16]. The leadership system must agree that promoting the new initiative is a core part of the company's strategy, reflect on the way their own behavior reinforces or inhibits it, and decide how they should role-model the change and engage all people involved in the change process [17].

Table 2. SMB framework for the adoption of systems thinking in organizations [11].

\begin{tabular}{|c|c|c|}
\hline Systems of Spirit & Systems of Mind & Systems of the Body \\
\hline $\begin{array}{ll}\text { - } & \text { Vision } \\
\text { - } & \text { Mission } \\
\text { - } & \text { Values } \\
\text { - } & \text { Strategy } \\
\text { - } & \text { Governance } \\
\text { - } & \text { Communication } \\
\text { - } & \text { Feedback systems [6] }\end{array}$ & $\begin{array}{ll}\text { - } & \text { Surface structures: } \\
\text { - } & \text { Training up to L1-L2 levels } \\
\text { - } & \text { Deep structures } \\
\text { - } & \text { Training and coaching up to L3-L4 level } \\
\text { - } & \text { Recognition and reward systems } \\
\text { - } & \text { Change management systems [18] } \\
\text { - } & \text { Mental models [1] } \\
\text { - } & \text { Feedback systems [6] }\end{array}$ & $\begin{array}{ll}\text { - } & \text { Tools for ST } \\
\text { - } & \text { Training material for ST } \\
\text { - } & \text { Company Wide intranet } \\
\text { - } & \text { Knowledge management systems } \\
\text { - } & \text { FAQs }\end{array}$ \\
\hline
\end{tabular}

Attention to "communication" is critical. In more successful transformational implementation efforts, executives use all existing communication channels to broadcast the vision. "They turn boring and unread company newsletters into lively articles about the vision. They bring out exciting material and generate interesting discussions on the new initiative" [18]. A transformational implementation is 5.8 times more successful at organizations where CEOs communicate a compelling, high level change story, and 6.3 times likelier when senior leaders share aligned messages about the change effort to the rest of the organization [16]. There is a need for "feedback systems" for continuous learning from success and failures and communicating the same to the rest of the organization [6].

If the systems of the spirit are positive, strong, and emotionally in tune with the new initiative, then the culture of cooperation prevails in the organization for the adoption of the new initiative with less room for political factors derailing the adoption process. In such a system, the role of the champion (or the internal networker) for promoting the adoption of the initiative is less daunting. If the systems of the spirit are weak, then the champion's spirit to achieve adoption can get dampened by the numerous hurdles in the organization for it to succeed.

\section{Systems of the Mind}

Systems of the Mind (for adoption) can be divided into two levels viz. deep structures and surface structures (Table 2). Deep structures enable change in thinking and working habits of the people involved [19] to such an extent that it lifts the organization to a higher level [20]. This is a transformational effort involving deep learning, which is classified in Kirkpatrick's [21] classification of learning levels (accessed 2015) as L3 and L4. L3 is the ability to apply the learning on the job aided by the organizational processes and systems that reinforce, encourage, and reward improved performance on the job due to new learning. This level of learning can result in behavioral change. Level 4 (L4) learning is tracking results through appropriate lead indicators suggesting that the critical behaviors are on track.

Level 1 and level 2 learning happens during training sessions which use some simple illustrative exercises during the session which will only help in awareness about the subject and are not good 
enough to change the behavior of the people. Levels L3 and L4 recognize the need for slack time and provide for it in the workplace for making trials with the new initiative. Typically, if the organization stops with L1 and L2 level learning, one often hears the comments from managers such as: "Forget what happens in the training, that is not how we do it in the office here "[20]).

Knowledge-networks and communities-of-practice (COP) [22,23] facilitate L3 and L4 level learning. These are practices which help connect like-minded people from diverse settings in an informal way and make them aware of each other's learning efforts. Gradually, they may help in developing the formal coordination and steering mechanism needed to move from local experiments to broader organization-wide learning (example, [24]). These networkers can identify the early-adopter community [25] for trying out the new initiative initially.

Change management: There are many change management approaches and frameworks. One simple and effective one is the $3 R$ framework suggested by [26]. The 3Rs are: Relate, Repeat, and Reframe. Detschman [26] gives several examples of how the 3R model can be used in different contexts for bringing about effective change.

\section{Systems of the Body}

Systems of the body are the supporting systems for the implementation of ST in the organization. These include the design and implementation of ST models and tools, creatively designed training material for training and workshops, case studies to reinforce learning, FAQs and documentation. They also include company intranet, helpdesk, blogs, and other such supporting organizational tools and artifacts. Systems of the body evolve based on the systems of the mind, which in turn are motivated by the systems of the spirit.

Although the three systems - spirit, mind, and body (SMB) — are depicted as separate entities as subsystems, it is only for convenience of discourse, and all three are interdependent and work together as a total system. It is only when they act as an interrelated system that the chances of the successful adoption of any new initiative and its sustained use in the organization becomes high. The SMB model proposed in this paper is defined for the limited purpose of understanding adoption problems of new initiatives such as ST in organizations. We do not claim any completeness of the elements proposed in each subsystem, but felt that they are adequate to aid the current discourse.

\section{How the SMB Model Explains the Success and Failure of Implementation in the Chosen Cases}

The two examples which follow demonstrate that the employment of SMB improved the overall success of the adoption of ST.

\subsection{ST Implementation at Ford}

Seligman [11] described the ups and downs in building an ST culture at Ford Motor Company during the mid-1990s and mid-2000s. The article reported the remarkable results the company achieved in bringing out new car model launches in early 2000s that were accomplished with better communication, less rework, and improved cost performance due to the implementation of ST by a handful of systems thinking champions after attending some masterly training programs given by Senge, Russel, and Ackoff. The training by the masters apparently ignited the interest of many people towards ST, which forever changed their way of looking at the world. However, reports that the training during this era was characterized more by "learning for the sake of learning" without sufficient focus on real-world problems [11]. Thus, the learning of the trained people can be assumed to be of L1 and L2 levels with no organizational support for learning and implementation at the workplace (which is L3, L4 learning).

However, these initial successes were not consolidated by the company in building the ST culture in the organization. There were apparently some CEO changes during this period, and their interest varied from support to disinterest. In 2001, the company hired a new CIO who had taken interest in reviving the previous ST glory and hired an expert consultant, Seligman, who could create a phased 
comprehensive curriculum for teaching ST in the corporate environment. He was also able to attract university students for intensive ST training in the Ford environment who could do some real-world projects in some sort of learning labs he created. Additionally, he was also able to attract some employees for similar ST training who were also able to tackle some real-world projects in the learning labs. As the word spread about the initiative, many project requests also started coming in. However, Seligman opted for capacity building by creating an expanding base of advanced practitioners first, rather than utilize the limited practitioners for projects. His primary goal in the few projects he accepted was to improve the learning of the people towards ST, rather than press for business results [11].

At the time of writing his narrative about the Ford initiative, he indeed expressed reservations about the sustainability of the initiative, which he felt is an emergent phenomenon that will depend on a large number of factors, many of which are out of one's control (e.g., leadership changes and the changes in the broader business environment). All along, he was wary of the company's "immune system" - "the instinctive response of the core business units of organizations to reject anything foreign". He was continually trying to work around it rather than disturb it in any way [11].

Tata Consultancy Services (TCS) in India also started a systems initiative in the early 1980s and continued it for more than 25 years. It was headed by Prof P.N. Murthy [27], who developed the knowledge base, tools, and training material for the introduction of ST in the organization. However, the initiative faced almost the same problems in implementation as that of Ford, as observed by Prof. Murthy [27] in a private conversation during 2015 when the Ford case was shown to him.

\subsection{Implementation of "Work Out" at GE}

GE introduced ST in its "GE WorkOut" initiative [12], which is a key organizational initiative to bust bureaucracy and silos and keep the company agile and innovative. The "WorkOut" initiative mandates stretch goals which can only be achieved by working across functions in the organization, and most often by connecting people outside the firm such as suppliers and customers. Such an attitude is facilitated by inculcating ST habits which encourage holistic thinking and appreciation of new emerging insights and multiple perspectives.

The "WorkOut" initiative was driven passionately by the then-CEO Jack Welch (systems of the spirit) to make it the company's organizational DNA. It is not true that GE did not face the resistance of the "immune system" for this change initiative, as happened at Ford. In fact, many business leaders and their direct reports were not willing to participate in the "WorkOut" initiative to start with. However, Jack Welch's relentless push and the interest "WorkOut" had generated in the younger community of the business units made the business leaders relent, and subsequently made them participate in the initiative. Excellent training programs were designed so that the whole organization can learn and implement the methodology. There was also close attention paid to change management aspects, since the very design of the "WorkOut" process is aimed at organizational change (systems of the mind). For example, "WorkOut" projects involve cross-functional and interdepartmental teams, town hall meetings, instant decision making by managers, and monetary support for new ideas right at town hall meetings without going through long bureaucratic hurdles for their implementation [12]. The company had built the necessary processes and tools and techniques (systems of the body) for the implementation of the work-out, such as: nominal group technique, affinity diagrams, Idea prioritization matrix, etc., in addition to the supporting tools to track progress [12]. Thus, GE's holistic attention to all three subsystems of Spirit, Mind, and Body enabled the "WorkOut" initiative to take firm roots in the organization, and in the process, ST had also taken firm roots, though the level of ST training offered was perhaps of a basic level when compared to that of Ford.

Although "WorkOut" was top-down driven, it was inclusive. In the words of [12], "WorkOut did not appear fully formed like Venus from the sea. Starting from Jack Welch's vision of what GE could become, work out evolved from the efforts of thousands of people struggling, learning and grappling together to translate the vision into reality". 


\section{Discussion}

Viewing Ford's experience from the point of view of the SMB framework, the narrative did not mention anywhere about the CEOs lending the much-needed "spirit" to the initiative and taking action towards the introduction of any effective governance and change management systems. The fact that different CEOs showed different kinds of interest towards ST indicates that there was no constancy of purpose or long-term strategy for the initiative. There was no attempt to break the silos which existed in the form of the "immune system". Thus, the leadership system (Table 2) related to systems of the spirit was weak.

The climate for learning up to L3, L4 levels which will enable people to carry out real-time projects apparently existed only in the learning labs in the IT division, and did not spread across the organization. The business divisions apparently did not create the necessary organizational processes and systems that reinforce, encourage, and reward improved performance on the job due to the learning of ST. In fact, Seligman had to suggest his own strategies to the trained people for use of their ST learning in their work environment without facing discouragement from the immune system [11]. Thus, the systems of the mind were weak (Table 2).

In contrast, one can notice from the GE "WorkOut" case that the initiative conformed to the requirements of the three subsystems of spirit, mind, and body as outlined above.

The ST-related training in "GE WorkOut" might have been of basic level when compared with the advanced-level training offered at Ford, but it was effective enough for people to cultivate habits like forming teams across departments and divisions and thinking holistically in solving problems, keeping the larger organizational requirements in view. The company took pains to break its "immune system" so that it did not form silos and get in the way of implementation of the new initiative. This is in conformance with systemic thinking.

Since "WorkOut" is a systemic initiative, its introduction in the organization prior to an ST initiative can evolve a conducive environment with helpful systems and structures. In fact, many people attribute the outstanding success of the six sigma initiative by GE to its prior "WorkOut" initiative (example, [28]). Indeed, six sigma with its statistical rigor is of a higher level of complexity for learning than a simple "WorkOut". Still, the company could achieve good organizational adoption for it, which some other companies which implemented six sigma without the workout base could not do. This observation raises the question whether companies who are seriously interested in initiating ST in their organization would do well to introduce "WorkOut" as a warm-up initiative to start with (example; [29]). After all, "WorkOut" has an ST step in its process, and such a warm up initiative can ingrain the basic ST thinking habits throughout the organization, making the resistance to new or advanced ST initiatives low.

The Ford ST initiative indicates that learning a complex subject like ST might not have been as much a problem for it (since many people could get trained and could successfully work on real-world projects) as its ability to break its "immune system". Breaking the "immune system" is the responsibility of the leadership. Systemic thinking can prompt the leaders towards taking such unpopular and hard decisions.

Thus, one can see that the SMB framework is helpful in having an intelligent discourse about the implementation of ST or similar initiatives in companies. It can also be useful for companies which have ideas of introducing ST in their organizations. Such companies can assess right in the beginning about their strength in leadership, change management, learning and feedback systems, and their competence in building the required tools before plunging into the introduction of ST. Merely hiring some ST experts without paying adequate attention to the required systems and structures will only give suboptimal results leaving the risk of sustainability of the initiative open.

The SMB framework discussed above is built based on our experience of studies on innovation adoption in organizations. It is by no means complete or final. There is scope for refinement of the model by studying more successful ST initiatives. 


\section{Summary}

In this paper, we examined the importance of systemic thinking and the need for appropriate system models for the implementation of systems thinking (ST) in organizations. The system model we used is based on the spirit, mind, and body (SMB) of the organization, which we defined in terms of systems of the spirit, systems of the mind, and systems of the body. The systems of the spirit is essentially the leadership system, systems of the mind are the learning and change management systems, and systems of the body are the tools and technology which aid the implementation of the initiative. Examination of the Ford ST initiative case using this model shows that systems of the spirit and the systems of the mind are weak in spite of the fact that the company developed excellent training programs and trained a fair number of people in advanced ST who could do real-time ST projects. This indicates that leadership and change management systems were not adequate for the initiative to take roots in the organization. On the other hand, when the model is applied to the GE "WorkOut" initiative (which is widely considered as one of the most successful organizational change initiatives in the corporate world), it showed that the company paid significant attention to most of the elements contained in three subsystems of the SMB model. The model and the current study gives some ideas for those aspiring to introduce ST in their organizations, what is involved in the introduction of ST and in sustaining it. The study shows that attention to the leadership and change management systems are more critical to the sustenance of the initiative than merely investing in specialists, training programs, and carrying out a few projects. A future study that might yield meaningful insights would be the study of an attempt to implement ST in a sub-optimal environment using $\mathrm{OMB}$ and measuring the results.

Acknowledgments: The author wishes to thank, Gene Bellinger, P.N. Murthy and Doji Simon for reviewing the manuscript at different stages of its evolution and offering helpful suggestions. Special thanks to the journal reviewers of this paper whose comments helped to shape up the paper in the present form-much different from the version first submitted.

Author Contributions: All of the authors wrote and revised the paper.

Conflicts of Interest: The authors declare no conflict of interest.

\section{References}

1. Morgan, P. The Idea and Practice of Systems Thinking and Their Relevance for Capacity Development. Available online: http:/ / portals.wi.wur.nl/files/docs/SPICAD/13.\%20Idea\%20and\%20practice\%20of\% 20systems\%20thinking\%20(ECDPM).pdf (accessed on 18 July 2005).

2. Senge, P.M. What is Systems Thinking? Peter Senge Explains Systems Thinking Principles and Approach. Available online: www.mutualresponsibility.org/science/what-is-systems-thinking (accessed on 18 July 2015).

3. Anderson, V.; Johnson, L. Systems Thinking Basics; Pegasus Communications, Inc.: Massachusetts, MA, USA, 1997.

4. Rousse, M. What Is Systems Thinking? Available online: http://searchcio.techtarget.com/definition/ systems-thinking (accessed on 18 July 2015).

5. Valerdi, R.; Rouse, W.B. When systems thinking is not a natural act. In Proceedings of the 5th IEEE Systems Conference, San Diego, CA, USA, 5-8 April 2010.

6. Ackoff, R.L. On Why Few Organizations Adopt Systems Thinking? Available online: http:/ /www.citeseerx. ist.psu.edu/viewbook/downloader=rep1\&type=pdf...1 (accessed on 18 July 2015).

7. Bellinger, G. Certified Systems Thinker Postscript. Available online: https://www.youtube.com/watch?v= 8B8C5eqNgpo (accessed on 18 July 2015).

8. Habits of Systems Thinker. Systems Thinking In Schools. Waters Foundation. Available online: http: / / watersfoundation.org/systems-thinking/habits-of-a-systems-thinker/ (accessed on 18 July 2015).

9. Parry, G.; Valerdi, R.; Nightingale, D.; Mills, J. Enterprise Transformation: Why Are We Interested, What Is It, and What Are the Challenges? J. Enterp. Transform. 2011, 1, 14-33.

10. Prasad, V.C.S.; Nori, K.V. Systems Approach for adoption of innovations in organizations. Syst. Pract. Act. Res. 2008, 21, 283-297. [CrossRef] 
11. Seligman, J. Building systems thinking culture at Ford Motor Company. Reflect. SoL. J. 2005, 6, 4-5.

12. Urich, D.; Kerr, S.; Ashkanas, R. GE Work-out-How to Implement GE's Revolutionary Method for Bursting Bureaucracy and Attacking Organizational Problems-Fast; Tata McGraw Hill: New Delhi, India, 2003; pp. $28-38$.

13. Nori, K.V.; Swaminathan, N. Cybernetic Modeling of Business Systems. In Proceedings of IEEE Conference on Norbert Wiener in the 21st Century: Driving Technology's Future, Boston, MA, USA, 24-26 June 2014.

14. Sri Arabindo. Essays on Gita, 10th ed.; Sri Arbindo Ashram Publication: Pondicherry, India, 1976.

15. Bolman, L.G.; Deal, T.C. Reframing Organizations, Artistry, Choice and Leadership; Jossey Bass Management Series; John Wiley \& Sons Inc.: New York, NY, USA, 1997.

16. Moer, D.; Reich, A.; Yocarini, L. The People Power of Transformations; Mc Kinsey Global Survey: New York, NY, USA, 2017.

17. Barsh, J; Capozzi, M.M.; Davidson, J. Leadership and Innovation. McKinsey Quarterly. Available online: http://www.mckinsey.com/insights/innovation/leadership_and_innovation (accessed on 18 July 2015).

18. Kotter, J.P. Leading change: Why transformation efforts fail. Harv. Bus. Rev. 1995, 3-4, 59-67.

19. Ken, W. A Sociable God: Toward a New Understanding of Religion, Vole 3; Shambhala Publications Inc.: Boston, MA, USA, 1983.

20. Deol, S. Surface and Deep Structures: An Integral Interpretation. Anchor Point 2002, 12, 12-16.

21. The New World Kirkpatrick's Mode. Available online: http://www.kirkpatrickpartners.com/ OurPhilosophy/TheNewWorldKirkpatrickModel/tabid/303/Default.aspx- (accessed on 18 July 2015).

22. Kanter, R.M. Innovation, the classic traps. Harv. Bus. Rev. 2006, 184, 73-83.

23. Hildreth, P.M.; Kimble, C. Knowledge Networks: Innovation through Communities of Practice; Idea Publishing: Hersey, ME, USA, 2004.

24. Senge, P.M. Rethinking leadership in the learning organization. Syst. Think. 1996, 7, 1-6.

25. Rogers, E.M. Diffusion of innovations, 4th ed.; Free Press: New York, NY, USA, 1995.

26. Deutschman, A. Change or Die; Harper Collins Publishers: New York, NY, USA, 2007.

27. Murthy, P.N. Private Communication, 2015.

28. Nayeem, N. The Story of Six Sigma and GE. Available online: http://www.brighthubpm.com/changemanagement/69148-the-story-of-six-sigma-and-ge/ (accessed on 18 July 2015).

29. Tucci, R. Six Sigma and Work Out. Available online: https://www.isixsigma.com/methodology/work-out/ six-sigma-and-workout (accessed on 18 July 2015). 